\title{
CONTRIBUIÇÃO DO PIBID PARA A FORMAÇÃO DOCENTE
}

\section{Mayara Cazadini Carlos ${ }^{1}$ \\ Lucyelen Costa Amorim² \\ Rafael Fonseca Rodrigues ${ }^{3}$ \\ Adriana de Medeiros Marcolano Thebas ${ }^{4}$}

Resumo: O Programa Institucional de Bolsa de Iniciação à Docência tem como objetivo a qualidade das ações acadêmicas voltadas à formação inicial de professores, incluindo os graduandos no cotidiano escolar. Com o objetivo de investigar quais são as influencias do PIBID na formação inicial dos acadêmicos do curso de Licenciatura foi elaborado e aplicado um questionário composto por oito questões objetivas e anônimas. De acordo com os dados obtidos, pode-se observar que os bolsistas apontam a importância do PIBID em seu futuro profissional, e que o PIBID aumenta a vontade de ser professor. Concluindo assim que é importante que o discente experimente a realidade escolar que é obtida através do projeto de iniciação a docência, pois, a partir dele é possível colocar toda teoria estudada, em prática.

Palavras-chave: PIBID; Formação inicial.

\footnotetext{
1 Ciências Biológicas, Instituto Federal do Espírito Santo Campus-Alegre, Brasil. E-mail: may_cazadini@hotmail.com.

2 Ciências Biológicas, Instituto Federal do Espírito Santo Campus-Alegre, Brasil, E-mail: lucyelen_amorim@hotmail.com.br.

3 Ciências Biológicas, Instituto Federal do Espírito Santo Campus-Alegre, Brasil. E-mail: rafael_rodrigues_10@hotmail.com.

${ }^{4}$ Letras, Faculdade de Filosofia Ciências e Letras de Alegre, Brasil. E-mail: marcolano20@hotmail.com.
} 